\title{
ESTRUTURA E DINÂMICA SOCIOESPACIAL DAS AGLOMERAÇÕES URBANAS EM TEMPOS DE GLOBALIZAÇÃO
}

\author{
Álvaro Luiz Heidrich \\ Iván Gerardo Peyré Tartaruga \\ Luciano Fedozzi \\ Paulo Roberto Rodrigues Soares \\ Rosetta Mammarella
}

A dinâmica contemporânea da economia, em face da crescente articulação dos lugares à globalização, tem implicado na absorção de novos padrões de organização da produção, trazendo consigo grandes e generalizadas transformações. As cidades, as aglomerações urbanas, e, de modo especial, as áreas metropolitanas, ao mesmo tempo em que assumem importância estratégica para esse processo, sofrem os impactos de suas mudanças, especialmente os efeitos que se verificam sobre o mercado de trabalho, com o aprofundamento das desigualdades sociais, da pobreza e dos riscos de intensificação dos processos de vulnerabilidade e exclusão social. $\mathrm{O}$ espaço urbano, igualmente, tem sofrido profundas alterações e, em especial, a fragmentação urbana se apresenta como sua feição mais expressiva. Esse conjunto de problemas, ao mesmo tempo em que compele as instituições para atuarem a favor das novas formas de reprodução do capital, também reclama do Estado novas concepções de política urbana, acompanhadas de novos instrumentos de ação e de gestão municipal.

Como ganham cada vez mais forte importância econômica, as grandes aglomerações urbanas do País constituem áreas que concentram riqueza e pobreza. Nelas têm-se acumulado consequências negativas tanto das transformações em andamento a nível mundial como das políticas internas de estabilização e ajuste fiscal, implementadas particularmente a partir da década de 1990. Enquanto no aspecto socioespacial isso se traduz por fragmentação e segregação, no âmbito das estruturas produtivas tem se caracterizado pelos processos de terceirização e terciarização aceleradas, desindustrialização relativa, movimentos de dispersão 
e/ou reconcentração econômica e territorial, transferência de plantas industriais, alteração das estruturas ocupacionais, por sua precarização, multiplicação de formas não organizadas de emprego, elevação da participação do setor informal na ocupação e na geração de renda, no desassalariamento e no desemprego estrutural.

A noção de fragmentação socioespacial, constituinte dessa nova configuração de tais áreas, materializa-se por um conjunto de processos excludentes que transformam a escala e a natureza da segregação urbana até então vigentes e repercutem aparente antagonismo: por um lado, a redução de sua escala e a consequente aproximação geométrica entre as classes dominantes e dominadas e, por outro, a redução do grau de interação entre grupos socialmente distintos em função do confinamento dos grupos superiores em espaços privados e da estigmatização dos espaços da pobreza como espaços da violência.

Os estudos desenvolvidos no conjunto desta obra pautam-se pela compreensão de uma vinculação entre a diferenciação socioespacial que decorre da crescente especialização de tarefas advindas do aumento da divisão social do trabalho. Ela gera diferenças de atributos, de recursos, de poder e de status, que se constituem nas bases materiais da formação de categorias sociais, as quais tendem a buscar localizações específicas na cidade, produzindo-se uma divisão social do território. Quer dizer: grava-se no espaço social da cidade aquilo que é coerente com as dinâmicas envolvidas.

Na perspectiva do conceito durkheimiano de solidariedade, a espacialização da diferenciação social não implica necessariamente segregação, podendo mesmo ser uma forma de integração societária, na medida em que a separação espacial dos grupos sociais estiver associada à existência de vínculos sistemáticos entre essas diferentes áreas socioterritoriais. Na perspectiva da ecologia humana, pelos processos de competição, a população é segregada em "áreas naturais", como unidades físicas nas quais se reconhecem individualidades de um povo segregado, em função de atitudes, sentimentos e interesses. A divisão socioterritorial da cidade pode, contudo, expressar não apenas a espacialização da diferenciação social, mas também a segmentação da sociedade. Esta ocorre quando se antepuserem barreiras que impedem a mobilidade social dos indivíduos entre as categorias sociais. Neste caso, a segmentação social implica na existência da segmentação espacial quando estas barreiras bloqueiam a mobilidade territorial - o que transformaria a divisão social da cidade em segregação residencial. A segregação residencial designa a situação na qual a segmentação da sociedade está fundada em uma crença coletivamente compartilhada sobre a necessidade da manutenção - ou mesmo aumento - das barreiras materiais ou simbólicas que bloqueiam a livre circulação dos indivíduos entre as categorias e, consequentemente, entre as localizações espaciais.

Essa concepção dos processos de organização social do espaço implica em avaliar as distâncias sociais existentes no território entre os grupos sociais ocupantes de posições distintas na estrutura social, as desigualdades de condições de vida e 
oportunidades que decorrem dessa organização e, finalmente, como as distâncias e proximidades implicam em padrões de interação e de sociabilidade. Ante as concepções mais tradicionais desse afastamento, de consistir em restrição à interação social (BOGARDUS, 1925), a distância social denotada pela intensidade das restrições à interação e diferenciação sociais associada à renda e níveis de instrução (SOROKIN, 1927), Pierre Bourdieu (1997) agrega mais fortemente a noção de espaço social que envolve esse problema. Em sua formulação, tal espaço se compõe por relações que envolvem as posições ocupadas por classes e grupos, os quais buscam conquistá-las e assegurá-las mediante práticas de dominação, portanto, não resumidas a aspectos denotativos de diferenças sociais. Dessa forma, o espaço social se estrutura a partir das intencionalidades que envolvem os portadores dos variantes tipos de capital, do econômico ao simbólico.

Além disso, compreendemos ser necessário considerar, também, que o espaço social de hoje se distingue pela incorporação de tecnologia. Ela altera substancialmente as relações, facilitando a articulação entre lugares e a realização de fluxos. Todavia, a participação de cada um depende da acessibilidade do seu lugar e das pessoas ao que Milton Santos (1996) denomina de meio técnico-científico-informacional. Se considerarmos a isso o que Raymon Ledrut (1968) indica como elementar para a estruturação da comunidade, a comunicação, hoje ela é cada vez mais constituída por conteúdo de informação, de dados, de conexões portadoras de funcionalidade. Não se tem, dessa forma, a mesma equivalência em termos de vivência entre as diferentes temporalidades ${ }^{1}$ do espaço social urbano.

Isso muda substancialmente as geografias que estamos habituados a reconhecer, pois estar no lugar, não significa exatamente vivê-lo. Primeiramente, além da estrutura física, a cidade é também a sua constituição social, "uma população estabelecida de maneira mais ou menos duradoura em um espaço até certo ponto bem delimitado, cujos membros mantêm relações de interdependência regidas por determinadas instituições” (LEDRUT, 1968, p. 23-24). Compreende, então, a distribuição dos objetos, os equipamentos, a urbanidade, as relações e dinâmicas espaciais, como de centralidade e periferia. Mas, além disso, sobre essa conformação a cidade é objeto da fragmentação de seu espaço, no qual distâncias físicas e sociais não possuem pertinências lógicas que não a do complexo jogo de posições derivadas da apropriação dos capitais e que, ainda, seu espaço se manifesta como um meio em que seu uso e apropriação dependem de acessibilidade econômica, instrucional e técnica. Ela se afasta, então, daquele sentido original, de constituir, de congregar uma comunidade.

1 "As atividades sociais produzem, cada uma ou quase todas, temporalidades específicas. As lógicas próprias a essas esferas de atividades tecem uma parte das tramas dessas temporalidades. $\mathrm{O}$ jogo dos atores coletivos cria uma outra parte. Imprime inflexões e confere direção a essas evoluções rítmicas. As formas temporais são intimamente ligadas às formas espaciais, às construções sociais; elas devem ser consideradas no mesmo movimento de interpenetração". (tradução livre). (DI MÉO; BULÉON, 2007, p. 21) 
Mantêm-se os vínculos formais apenas e se esfacela o seu conjunto em múltiplas realidades, estranhas umas com as outras.

Desse modo, o espaço social dessa cidade é também um compósito de múltiplos espaços sociais. Cabe considerar para esse contexto:

1. A concepção estrutural compreendida por Paul-Henry Chombart de Lauwe (1960) de setores funcionais e uma hierarquia de espaços, como o familiar, de vizinhança, econômico e um setor urbano.

2. A concepção de que o urbano é produzido pelo entrelaçamento das práticas espaciais de pessoas e grupos sociais, a representação hegemônica que se faz do espaço e os espaços de representação, ou vividos (LEFEBVRE, 1984). Portanto, mais distante de uma noção de substância e mais perto de uma noção pautada por relações.

3. As considerações que acusam a fugacidade do social abstrato imaginado na construção da modernidade e que advogam a perda de sentido (BERGER; LUCKMANN, 2004) ou o desencaixe (GIDDENS, 1990). Elas têm trazido a noção de exacerbação das individualidades e singularidades, da invasão completa do nosso mundo particular pelas necessidades dos outros, externadas como gerais (SENNET, 1988), de esvaecimento das referências da política e dos sensos e códigos da civilidade (GOMES, 2002) e de que o espaço público também se perde e se privatiza cada vez mais (SERPA, 2007).

4. De que não é uma construção ou projeto sociopolítico que resume sua compreensão, mas um espaço de tudo isso, sobre o qual se efetiva o jogo das posições, pela posse de capitais, conforme a proposição de Pierre Bourdieu (1989).

Esse espaço social, que se instaura por sobre o espaço anterior, a cidade que lhe dá origem, está profundamente ligado à produção de novas centralidades, espaços de consumo e habitação fechados, que tendem a anular prerrogativas da temporalidade anterior, como relações de vizinhança e até formalidades sociais que codificaram a vida coletiva ${ }^{2}$. Muito embora tudo permaneça em relação, nem tudo está organicamente interligado, seja por causa do aprofundamento dos mecanismos de segregação, seja por causa da perda da coesão comunitária.

Como a cidade é fruto das condições históricas implicadas no capitalismo (LEFEBVRE, 2001), ela não garante lugar para a população sem ou com pouco

2 Não se deve desconhecer que essas características no espaço social da cidade já vinham se manifestando antes mesmo da exacerbação técnica dos dias atuais, mas como um fato associado ao aparecimento das profissões de classe média e alta, sua correspondente sensação de participação num mundo equitativo e de predominância das relações formais e a correspondente redução da ajuda mútua na vida de bairro (LEDRUT, 1960). 
rendimento. A propriedade privada do solo urbano faz com que uma renda para pagar por seu uso seja fundamental, não apenas para a ocupação do espaço, mas também para a sua reprodução. Necessidades básicas de trabalhadores, de pessoas sem propriedade de capital, são limitadas, se não impossíveis em tal espaço social. Por isso, quando tais necessidades deixam de ser objeto da política pública, ou quando esta é ineficaz, o comum é a generalização de ocupações clandestinas, irregulares, segundo a lógica do espaço urbano capitalista. Elas passam a constituir um componente próprio do espaço social da cidade. Mesmo que não seja lógico à organização formal da cidade capitalista, contraditoriamente, a massa de trabalhadores com parcos recursos para sua sobrevivência é uma condição extremamente favorável para a reprodução do próprio capital (BONDUKI; ROLNIK, 1979).

Via de regra, a ocupação irregular do espaço urbano é similar ao processo de constituição das suas periferias. As condições de localização mais distante, áreas sem infraestrutura básica, como saneamento, escolas, serviços de saúde e transportes, são as características mais comuns associadas a tal formação. Esse contexto mistura, em geral, duas práticas sociais: a busca de moradia e de condições de reprodução social. Em qualquer exercício de reconstituição da memória de formação dessas áreas, identifica-se na reunião das diversas experiências de seus moradores que a busca pela casa e por atividades de sustentação da vida se confundem com a própria história das pessoas, como essências do espaço vivido.

Do ponto de vista da relação com o capital, periferias são "parcelas do território da cidade que têm baixa renda diferencial” (BONDUKI; ROLNIK, 1979, p. 147), e costuma-se reconhecer como áreas em que há ausência ou carência dos atributos do espaço urbanizado. Atualmente, porém, em função das mudanças nos padrões de uso do solo urbano, que combina a busca de amenidades naturais com a implantação dos chamados enclaves fortificados (CALDEIRA, 2000), a proximidade física da precariedade urbana da periferia e dos condomínios fechados tem sido bastante comum.

Aparece, por isso, um aspecto singular da segregação urbana, que denota bastante uma das faces da fragmentação que pode ser entendida como fratura socioespacial (HEIDRICH, 2007), à medida que proximidade física e distanciamento sociocultural configuram fatos associados. Tal perspectiva do espaço social da cidade também é reconhecível pelo deslocamento dos processos constituintes de periferia para locais de centralidade, com densidade de serviços e infraestrutura urbana. É o que ocorre com as ocupações de cantos e nesgas de lotes urbanos e de áreas públicas. É comum que em tais ocupações o risco à reprodução da vida seja maior. Características dessas áreas são, por exemplo: a inexistência de saneamento básico, às vezes sem abastecimento de água, outras vezes centenas de pessoas repartem uma bica; serem áreas inundáveis às margens de córregos, em geral escoadouros de esgotos; ausência de calçamento etc. Porém, tudo isso muitas vezes junto a espaços 
plenamente incorporados à cidade e, portanto, repletos de sentidos de urbanidade.

Considerando-se que a desigualdade socioespacial tem se caracterizado ao lado das urbanidades do meio técnico científico-informacional e dos enclaves fortificados, pela precariedade da periferia e das áreas de ocupação irregular e clandestina, compreende-se o espaço social como aquele em que o estranhamento, a segregação e a fratura são seus aspectos mais comuns.

Esse é o perfil de cidade que estranhamente é dos tempos de crescente integração socioespacial, em que a burla das grandes distâncias físicas torna tudo mais condensado, especialmente nas metrópoles e grandes aglomerações urbanas. Por sua natureza, agregariam com mais força o mundial, constituídas como exópolis (SOJA, 2001), como a dinâmica de cidade fora de seus núcleos e de cidades sem cidadanias, processos estes que amplificam a estratificação e as desigualdades sociais.

Nesse sentido, nossa hipótese é de que os processos socioespaciais em curso nas metrópoles e aglomerações urbanas consideradas nestes estudos, conceituados como diferenciação, segmentação e fragmentação, têm enorme importância na compreensão dos mecanismos societários de exclusão e integração, através de seus efeitos sobre a estruturação social, os mecanismos de produção/reprodução de desigualdades e as relações de interação e sociabilidade entre os grupos e classes sociais.

Nas últimas décadas, tem-se experimentado, junto às grandes aglomerações urbanas do Rio Grande do Sul - as regiões metropolitanas e os aglomerados urbanos ${ }^{3}$ e a virtual Cidade-região de Porto Alegre ${ }^{4}$-, forte pressão pela ocupação das áreas urbanas, fato estreitamente associado às transformações do mercado de trabalho ocorridas nos anos 1980, 1990 e 2000.

Inserida no processo de globalização, a urbanização no Rio Grande do Sul apresenta um forte dinamismo ao desenvolver-se sobre uma rede urbana complexa que conforma distintas territorialidades. Entre estas encontra-se a metrópole de Porto Alegre, com mais de 1,5 milhão, e sua região metropolitana (RMPA), núcleo concentrado e polarizador da hierarquia urbana deste Estado. A RMPA é a quarta mais importante concentração urbana do Brasil. Sua extensão total é de $10.234 \mathrm{~km}^{2}$ ( $452 \mathrm{~km}^{2}$ no município da capital), com uma população de mais de quatro milhões de habitantes. É formada por 34 municípios que ocupam 3,70\% da superfície total do Rio Grande do Sul, do qual concentra 37\% dos habitantes.

Nos últimos anos, a RMPA vem apresentando diferentes mudanças na sua estrutura socioespacial. Entre elas, há a incorporação de novos territórios ao tecido

3 Região Metropolitana da Serra Gaúcha (anteriormente Aglomeração Urbana do Nordeste - AUNE); Aglomeração Urbana do Sul - AUSUL; e Aglomeração Urbana do Litoral Norte - AULINORTE.

4 A Região Metropolitana e as aglomerações urbanas do seu entorno (Caxias do Sul, Santa Cruz do Sul, Lajeado-Estrela), as quais formam um conjunto urbano em vias de integração, conformando uma "macrometrópole" ou uma cidade-região inserida na economia mundializada. 
metropolitano, a relocalização e a desconcentração dos espaços industriais em setores perimetropolitanos e a tendência à integração com outras aglomerações urbanas.

Podemos afirmar, então, que a Região Metropolitana de Porto Alegre tem seguido as tendências das metrópoles mundiais, observando-se o fenômeno da desconcentração e a fragmentação metropolitana. A título de exemplo, em 1970, aproximadamente $57 \%$ da população metropolitana vivia em Porto Alegre; enquanto que, em 1980, essa proporção reduziu-se para próximo de 50\%. Esta tendência se confirmou no Censo 2000, no qual se constatou quase $2 / 3$ da população metropolitana vivendo fora da capital. O município de Porto Alegre vive um acelerado processo de terciarização, com $84 \%$ do PIB e $72 \%$ da força de trabalho empregada neste setor (IBGE, 2003).

Enquanto o setor terciário destacadamente se desenvolve no município núcleo, acelera-se a chamada "desconcentração concentrada" e o desdobramento da indústria sobre os eixos de conexão da RMPA com o interior do Estado, especialmente em direção a Caxias do Sul (norte), Santa Cruz do Sul (oeste) e o Litoral (leste). O território metropolitano vai tornando-se mais homogêneo, pela dispersão dos fixos e dos sistemas de infraestrutura, e mais hierarquizado, tendo Porto Alegre como centro de gestão.

O entorno metropolitano - com muitos de seus municípios já considerados industrializados - desde a metade da década de 1990 é cenário da localização de muitos dos novos empreendimentos industriais. Destacam-se nele municípios periféricos ou adjacentes à RMPA (Montenegro, Igrejinha), a aglomeração de Santa Cruz do Sul (com mais de 150 mil habitantes urbanos), importante concentração da indústria fumageira, e o conjunto Lajeado-Estrela (com mais de 100 mil habitantes urbanos) de indústria diversificada, localizada sobretudo no eixo da rodovia BR-386. Deve-se considerar ainda o movimento de desconcentração metropolitana rumo ao Litoral Norte do Estado, seguindo o eixo das BRs 290 e 101, e que se configura como alternativa locacional para o capital industrial, bem como se constitui a região com maior crescimento populacional do Estado na última década.

Os principais aspectos dessas modificações são o crescimento da ocupação precária, informal, transitória, especialmente no setor de serviços em geral e, particularmente, nos serviços pessoais e domésticos. Acompanha essa dinâmica uma profunda crise da mobilidade urbana e o colapso das formas de provisão da moradia.

Como a riqueza vem se mantendo concentrada nos municípios polos, compreende-se que à organização social do território no contexto da reestruturação das atividades econômicas das metrópoles e aglomerações urbanas associa-se o conflito pela centralidade na ocupação e uso do solo urbano. Duas outras expressões desse conflito são, de um lado, a imobilidade de parte da população trabalhadora e, de outro, a reprodução da precariedade do habitat urbano. 
Atravessamos igualmente, como tem ocorrido nas grandes metrópoles nacionais, uma crise social que envolve a fragilização do bem-estar social e das estruturas sociais no plano da família e do bairro, combinadas aos mecanismos de segregação residencial. Três tendências se entrelaçam na produção dessa fragilização das estruturas sociais familiar-comunitárias: (i) por um lado, a crescente incorporação dos territórios populares à ordem mercantil, que atinge não somente a moradia tanto pela expansão da compra e venda, como pelo aluguel do imóvel -, mas todo um conjunto de economia local que funciona sob bases institucionais paralelas às formais; (ii) a difusão de uma sociabilidade violenta (MACHADO DA SILVA, 2004) como ordem social e suas conseqüências na vida coletiva desses territórios; e, (iii) como substrato material dessa sociabilidade, as tendências à concentração territorial de segmentos sociais - literalmente, populações - vivendo relações instáveis com o mercado de trabalho e outras consequências, como o isolamento sociocultural face ao conjunto da cidade.

Os três mecanismos se reforçam mutuamente, transformando a segregação residencial em uma das principais marcas da atual ordem urbano-metropolitana. Observamos em nossos estudos evidências empíricas nessa direção. Além das já conhecidas tendências ao autoisolamento das camadas superiores em "cidadelas fortificadas” - conhecidas como condomínios fechados -, constatamos a formação de territórios concentrando uma população vivendo o acúmulo de vários processos de vulnerabilização social, que apontam para a tendência à reprodução da pobreza e das desigualdades. São bairros periféricos e favelas que concentram pessoas com laços instáveis com o mercado de trabalho e vivendo sob condições de fragilização do universo familiar. São territórios que tendem a concentrar uma espécie de capital social negativo. Em estudo realizado pelo Observatório das Metrópoles (RIBEIRO; SANTOS JR., 2007), constatamos que o risco de jovens entre 17 e 24 anos de estar em situação de desafiliação institucional, ou seja, não estudar, não trabalhar e nem procurar ocupação - aumenta $30 \%$ entre os moradores de bairros com forte concentração de responsáveis pelo domicílio que mantêm frágeis e instáveis laços com o mercado de trabalho. O risco de desproteção escolar-familiar de crianças e jovens de 4 a 14 anos aumenta em $28 \%$ se o domicílio se encontrar localizado nesses mesmos bairros.

A segregação socioespacial não tem sido apenas efeito, pois termina por assumir papel condutor da reprodução das desigualdades no que concerne à distribuição do poder social na sociedade, entendido este como a capacidade diferenciada dos grupos e classes em desencadear ações que lhes permitam disputar os recursos urbanos. Esta capacidade depende do quanto a concentração espacial conduz à sociabilidade indutora da construção de comunidades de interesses. Estamos, então, colocados diante do desafio histórico de construção de um regime institucional de gestão dos territórios metropolitanos capaz de articular os atores do Estado, do mercado e da 
sociedade em torno de ações de cooperação e complementaridade eficaz, eficiente, justa e sustentável.

Nesse sentido, tem sido possível observar alguns movimentos - experiências que vislumbram certa capacidade de articulação das instâncias federativas, notadamente representado pelo revigoramento de instâncias locais. A redemocratização do país, com a nova Constituição de 1988, determinou uma estrutura federativa inédita do Estado democrático, pois favoreceu a descentralização político-administrativa e a desconcentração dos recursos com partilha mais equânime da arrecadação em favor de Estados e municípios - em que pese a posterior reconcentração pela União a partir da Lei de Responsabilidade Fiscal aprovada nos anos 1990. De qualquer forma, o caráter de ente federado assumido pelos municípios (em situação de igualdade perante os Estados e a União), constituiu rara inovação democrática no panorama mundial.

Esse processo de profundas transformações na estrutura socioeconômica e no arcabouço político-institucional do País foi acompanhado do surgimento, a partir do final dos anos 1970 e início dos anos 1980, de novos atores sociais e de novas práticas político-culturais no contexto da ampliação e da vitalização da sociedade civil e da esfera pública, indicando que, apesar da crise e da fragmentação social, formou-se um quadro fecundo de construção do espaço público brasileiro. Uma parcela desses atores sociais passou a expressar um discurso baseado na noção de direitos da cidadania de forma relativamente inédita.

No âmbito das relações entre o Estado e a sociedade, a transição à democracia trouxe consigo o crescimento de experiências de participação na gestão das cidades (inclusive capitais de Estados que readquiriram o direito de eleger seus prefeitos), adotando práticas mais favoráveis à participação das camadas historicamente excluídas das decisões e da condição de cidadania. Nesse processo de proliferação de instituições participativas, desde a Constituição de 1988, destacam-se os Conselhos Gestores de Políticas Públicas e Conselhos de Direitos; os Orçamentos Participativos; os Planos Diretores Participativos; as Conferências Nacionais; as Audiências Públicas, dentre outros processos. Nesse leque de inovações participativas, os Orçamentos Participativos vêm se destacando ${ }^{5}$ nos cenários nacional e mundial como uma das práticas inovadoras da democracia participativa, em especial na esfera local ${ }^{6}$.

5 O caso de Pelotas, em 1982, foi pioneiro nesse sentido, embora outras experiências participativas já existissem desde a década de 1970, como é o caso de Lages (RS) e de Boa Esperança (ES).

6 Conforme dados do Fórum Nacional de Participação Popular, o número de casos passou dos cerca de 10, registrados no período 1989 a 1992, para 30, entre 1993 e 1996, e em torno de 140, entre 1997 e 2000 (RIBEIRO; GRAZIA, 2003). O período seguinte apresentou crescimento ainda maior, com 190 cidades em 2001-2004, e 201 em 2005-2008 (WAMPLER, 2008). Conforme o último censo da Rede Brasileira de OP, o número chegou a 355 no período 2009-2012 (REDE..., 2012). Para análise desses casos ver FEDOZZI; LIMA; MARTINS (2014). Percebe-se rápida ampliação de cidades no mundo que estão adotando modelos autodenominados de Orçamentos Participativos (muito distintos entre si, como no Brasil). Estima-se, hoje, que sejam em torno 2,7 mil cidades em praticamente todos os continentes do mundo (SINTOMER et al., 2013). 
Os estudos atuais sobre essas duas décadas de participação, no Brasil, apontam avanços, mas também limites, principalmente quanto à efetividade sobre as políticas públicas (PIRES; LOPES, 2010). No entanto, apesar de todos os avanços, são identificados diversos bloqueios e dificuldades para o efetivo funcionamento dessas instâncias, destacando-se os problemas de capacitação e ausência de instrumentos de gestão e monitoramento de políticas públicas. Em muitos casos, elas possuem caráter meramente formal, expressando situações de fragilidade da sociedade civil local/regional e/ou descompromisso governamental com a real democratização das decisões públicas. Essas características também ocorrem quando as instâncias participativas são criadas a partir de vontades exógenas ou heterônomas à dinâmica real dos atores locais. É o caso de grande parte dos Conselhos dos Planos Diretores de Desenvolvimento Urbano (SANTOS JR.; MONTANDON, 2011), inovação introduzida pelo Estatuto das Cidades (BRASIL, 2001) e que representou a regulamentação do capítulo da política urbana aprovado pela Constituição Federal de 1988. Com efeito, a política urbana do País vem sofrendo regressão pelo menos desde 2004, trazendo consigo bloqueios para a implementação da agenda da reforma urbana no País (MARICATO, 2011; ROLNIK, 2009).

Efetivamente, a esfera local propicia - na vida cotidiana e na interação entre governantes e atores da sociedade civil -oportunidades de ação, de construção de habilidades e de aprendizagens coletivas e individuais que podem adquirir conteúdos universais, tanto materiais como normativos. Não obstante, faz-se necessário lembrar que a participação local, assim como a descentralização, não significam per se mais democracia ou transformações sociais. A análise de experiências de descentralização na América Latina e no Brasil, por exemplo, revela o caráter ambíguo dessa relação entre gestão local, democracia e cidadania (ARRETCHE, 1996, 2000; ABRUCIO, 2002; MELO, 1993).

Participação e descentralização deixam de ser portadoras de fim democrático em si mesmo, uma vez que a elas correspondem relações de poder nas formas de produção da opinião e da vontade política. Nesse quadro, os municípios constituem territórios de disputa e de incerteza quanto aos reais efeitos da participação em termos de justiça distributiva, de eficácia governamental, de controle social sobre o Estado e de transformação da consciência social.

As questões, dinâmicas e problemas aqui introduzidos são o foco dos estudos que compõem este livro. A grande maioria das pesquisas das quais resultam os artigos fizeram parte do projeto "Estruturação territorial, dinâmica socioespacial e governança: efeitos e transformações nas Aglomerações Urbanas do Rio Grande do Sul - 1991/2010"7, o qual reuniu equipes interdisciplinares de duas instituiçõoes com tradição na pesquisa dos temas urbanos deste Estado: a Fundação de Economia e 
Estatística Siegfried Emanuel Heuser, por meio do Núcleo de Estudos Regionais e Urbanos e do Núcleo de Análise Setorial; e a Universidade Federal do Rio Grande do Sul, por meio dos programas de pós-graduação em Arquitetura, Geografia e Sociologia, do Departamento de Medicina Social da Faculdade de Medicina e do Departamento de Urbanismo da Faculdade de Arquitetura.

A metodologia geral empregada no projeto fundamentou-se na adoção de uma mesma territorialidade - no caso, o território das aglomerações das aglomerações urbanas do Rio Grande do Sul, permitindo evidenciar inter-relações que vão da infraestrutura física às atividades econômicas, às relações sociais e políticas, as quais, ao realizarem-se sobre um mesmo território, dizem respeito a um espaço integrado, embora com as vicissitudes pertinentes à dinâmica de globalização, notadamente o recrudescimento da segregação e a sua face atual de fragmentação socioespacial.

São comuns nos estudos propostos a questão urbana e os processos de diferenciação, de desigualdades, de segmentação, segregação e fragmentação do espaço e das relações sociais, que são investigadas em várias dimensões e diferentes escalas. A discussão e compartilhamento de fundamentos teórico-metodológicos, e a adoção de técnicas e procedimentos de uso e tratamento de dados de modo articulado traz para esta obra um diagnóstico bastante amplo sobre a realidade social e urbana do Estado.

O grupo de pesquisadores esteve articulado no Núcleo Porto Alegre do Observatório das Metrópoles, atualmente sediado e acolhido no Instituto Latino Americano de Estudos Avançados da Universidade Federal do Rio Grande do Sul. O Observatório das Metrópoles constitui uma rede nacional de pesquisa, congregado por 59 instituições nacionais, voltadas para a pesquisa sobre a metropolização do país e atualmente integra o Programa Institutos Nacionais de Ciência e Tecnologia (INCT/CNPq/FAPERJ).

No projeto desenvolvido pelo Núcleo Porto Alegre, do Observatório das Metrópoles, a intenção de aproximação com outros grupos de pesquisa sobre o espaço e as questões urbanas resulta aqui neste livro, na colaboração de equipes da Universidade do Rio Grande e da Universidade de Santa Cruz do Sul.

Além deste texto introdutório, este livro contém mais 12 capítulos que estão divididos em quatro partes. A primeira parte, composta por três capítulos, discute a Estrutura e dinâmica das aglomerações urbanas do Rio Grande do Sul nos seus aspectos sociais, ocupacionais, populacionais, espaciais e econômicos. Assim, o primeiro capítulo apresenta o Perfil sócio-ocupacional das aglomerações urbanas do Rio Grande do Sul, 2000-2010, de autoria de Gisele da Silva Ferreira, Mariana Lisboa Pessoa, Iván Gerardo Peyré Tartaruga e Rosetta Mammarella, e que relaciona esse aspecto com alguns indicadores demográficos, educacionais, de trabalho e de moradia, configurando um quadro geral compreensivo dos principais espaços urbanos do Estado. O segundo, de Bianca Reis Ramos e Solismar Fraga Martins, 
analisa a Dinâmica socioespacial a partir das transformações econômicas e industriais do setor naval/portuário na cidade do Rio Grande, RS, com base em informações demográficas e econômicas de recorte intraurbano e mostrando algumas tendências populacionais e das atividades produtivas desse importante município da AUNE. $\mathrm{O}$ terceiro, intitulado Urbanização e dinâmica socioespacial nas aglomerações urbanas da Região dos Vales, RS, realizado por Heleniza Ávila Campos e Rogério Leandro Lima da Silveira, aborda as transformações na urbanização e socioespaciais (sobretudo segregação e autossegregação) na região dos Vales do Taquari e do Rio Pardo.

A segunda parte do livro discute as Mudanças socioeconômicas das aglomerações urbanas do Rio Grande do Sul, que estão ocorrendo nas atividades comerciais e de serviços, e de produção de inovações e no papel das regiões como agentes de intervenção econômica, sendo integrada por três capítulos. Dessa forma, o quatro aponta As novas centralidades comerciais e de serviços na Região Metropolitana de Porto Alegre, de Paulo Roberto Rodrigues Soares e Anderson Müller Flores, que se originam de uma metropolização dilatada e de uma estruturação complexa, caracterizando os novos centros comerciais e de serviços, processos que são conduzidos pelo mercado imobiliário de caráter global. O quinto capítulo, denominado Crescimento e desenvolvimento: uma leitura da Aglomeração Urbana do Sul, de César Augusto Avila Martins, debate as possibilidades de inserção econômica dessa aglomeração na dinâmica nacional dentro dos limites e das oportunidades de intervenção no âmbito regional. Encerrando esse bloco do livro, o capítulo seis, nomeado A geografia econômica da metrópole e das aglomerações urbanas gaúchas: teoria e indicador do potencial de inovação, de Iván Gerardo Peyré Tartaruga, examina a dispersão espacial do indicador de potencial de inovação nas principais áreas urbanas do território gaúcho.

A terceira parte da obra, formada por mais três capítulos, trata das Desigualdades sociais, ocupação da cidade e conflitos, tendo um foco especial na problemática da violência metropolitana e das moradias precárias com impactos significativos na vida das pessoas e, também, no meio ambiente. O sétimo capítulo, de autoria de Letícia Maria Schabbach, aborda a Desigualdade, pobreza e violência metropolitana na cidade de Porto Alegre, relacionando fatos violentos (homicídios e lesões corporais seguidas de morte) com as características sociais dos respectivos bairros onde ocorreram os crimes. Além disso, analisaram-se as repercussões de algumas políticas públicas nesses bairros. Já o oitavo traz uma Análise da ocupação irregular em áreas de proteção ambiental na Região Metropolitana de Porto Alegre, RS, realizada por Mariana Lisboa Pessoa, que tem por objetivo identificar espacialmente esse tipo de ocupação nessas áreas ambientais, situação geradora de danos ao meio ambiente e à população relacionada, e, ao mesmo tempo, servir de base para a efetivação de políticas públicas vinculadas à regularização fundiária. No A ocupação irregular como estratégia de conquista da cidade. Enfoque sobre os aspectos territoriais do 
problema em Porto Alegre, título do nono capítulo, de Álvaro Luiz Heidrich, Amanda Cristina Bahi de Souza, Christiano Correa Teixeira, Marília Guimarães Rathmann e Rodrigo Costa de Aguiar, é debatida a questão da ocupação irregular nos espaços urbanos da capital gaúcha, principalmente no que tange à busca de direitos dos que vivem nessas áreas. Para isso, são examinadas cinco ocupações da cidade.

Por fim, a quarta parte, comportando os últimos três capítulos do livro, coloca em destaque a Participação na cidade examinando experiências relacionadas às áreas da saúde e da pavimentação e à situação dos jovens como partícipes em um processo decisório participativo. O décimo capítulo trata das Cidades, desigualdades e a dengue: lições de uma grande epidemia de dengue numa microárea de Porto Alegre, a Vila Sossego, de Maria Inês Azambuja, Alzira Lewgoy, João Henrique Kolling e Igor Espíndola. Neste artigo, é apresentada a experiência de profissionais da área de saúde trabalhando na identificação de uma epidemia de dengue nessa região da cidade, na qual houve a importante participação da população local. No capítulo décimo primeiro, Iára Regina Castello discorre sobre as Arenas decisórias no desenvolvimento urbano: pavimentação comunitária da Rua Carlos Supérti, examinando a urbanização de assentamentos precários efetivada por meio de um microinvestimento obtido pela participação da comunidade em processo decisório, mais especificamente, o Orçamento Participativo. E no artigo final, denominado Participação e juventudes: relações geracionais e adultocentrismo no Orçamento Participativo de Porto Alegre, João Paulo Pontes e Luciano Fedozzi debatem a atuação dos jovens dentro desse processo decisório frente à hegemonia dos adultos (adultocentrismo), portanto, em um quadro de dificuldades e de limitações à participação juvenil.

\section{REFERÊNCIAS BIBLIOGRÁFICAS}

ABRUCIO, F. L. A Experiência de Descentralização: Uma Avaliação. In: NASSUNO, M.; KAMADA, P. H. (orgs.). Balanço da Reforma do Estado no Brasil: a nova gestão pública. Brasília: Ministério do Planejamento, Orçamento e Gestão, 2002, p. 207-222. Disponível em: $<$ http://www.cedec.org.br/files_pdf/balancodareformadoestadonobrasil.pdf $>$. Acesso em: 18 dez. 2015.

ARRETCHE, M. Mitos da descentralização. Mais democracia e eficiência nas políticas públicas? Revista brasileira de Ciências Sociais, São Paulo, n. 31, ano 11, p. 44-66, jun. 1996.

BRASIL. Estatuto das Cidades: Lei 10.257/2001 que estabelece diretrizes gerais da política urbana. Brasília, Câmara dos Deputados, 2001.

BERGER, P. L.; LUCKMANN, T. Modernidade, pluralismo e crise de sentido. A orientação do homem moderno. Petrópolis: Vozes, 2004.

BOGARDUS, E. S. Measuring social distance. Journal of Apllied Sociology, n. 9, Nov/Dez. 1925. 
BONDUKI, N.; ROLNIK, R.. Periferia de São Paulo: reprodução do espaço como expediente de reprodução da força de trabalho. In: MARICATO, Ermínia. (Org.) A produção capitalista da casa (e da cidade) no Brasil industrial. São Paulo: Alfa-Ômega, 1979, p. 117-154.

BOURDIEU, P. O poder simbólico. Lisboa: DIFEL; Rio de Janeiro: Bertrand Brasil, 1989.

BOURDIEU, P. A miséria do mundo. Petrópolis: Vozes, 1997.

CALDEIRA, T. P. do R. Cidade de Muros: Crime, segregação e cidadania em São Paulo. São Paulo: Editora 34: Edusp, 2000.

CASTELLS, M. A sociedade em rede. São Paulo: Paz e Terra, 1999.

DI MÉO, G.; BULEÓN, P. L’espace social. Lecture géographique dês sociétés. Paris: Armand Colin, 2007.

FEDOZZI, L.; LIMA, K. C. P.; MARTINS, A. Desigualdade na ampliação das inovações participativas: características dos municípios com Orçamentos Participativos no Brasil. 380 Encontro Anual da ANPOCS. Caxambu/MG, 2014. Disponível em: <http://www.anpocs. org/portal/index.php?option=com_docman\&task=doc_download\&gid=8889\&Itemid $=456>$. Acesso em: 18 dez. 2015.

GIDDENS, A. As consequências da modernidade. São Paulo: Editora da UNESP, 1990.

GOMES, P. C da C. A condição urbana. Ensaios de geopolítica da cidade. Rio de Janeiro: Bertrand-Brasil, 2002.

HEIDRICH, A. L. Aspectos da fratura socioespacial na cidade de Porto Alegre. Scripta Nova, Barcelona, v. XI, 2007, p. 67.

IBGE. Censo demográfico 2000. Rio de Janeiro: IBGE, 2003.

LAUWE, P. C.. Lévolution dês besoins et la conception dynamique de la familie. Revue Française de Sociologie, Paris, v. 1, p. 403-425, 1960.

LEDRUT, R. El espacio social de la ciudad. Buenos Aires: Amorrortu editores, 1968.

LEFEBVRE, H. A cidade do capital. Rio de Janeiro: DP\& A, 2001.

LEFEBVRE, H. La production de l'espace. Paris: Anthropos, 1984.

MACHADO DA SILVA, L. A. Sociabilidade Violenta: por uma interpretação da criminalidade contemporânea no Brasil urbano. In: RIBEIRO, L. C. Q. (Org.). Metrópoles: entre a coesão e a fragmentação, a cooperação e o conflito. São Paulo: Ed. Perseu Abramo, 2004, p. 291-351.

MARICATO, E. O impasse da política urbana no Brasil. Petrópolis: Vozes, 2011.

MELO, M. A. B. C. Municipalismo, nation-building e a modernização do Estado no Brasil. Revista Brasileira de Ciencias Sociais, São Paulo, v. 8, n. 23, out. 1993.

PIRES, R. R.; LOPEZ, F. Instituições participativas e políticas públicas no Brasil: características e evolução nas últimas duas décadas. In: IPEA. Brasil em desenvolvimento 2010: Estado, planejamento e políticas públicas. Brasília: IPEA, 2010, v. 3., p. 565-585. Disponível em: < http://www.ipea.gov.br/portal/images/stories/PDFs/livros/livro_bd_vol3.pdf $>$. Acesso em: 18 dez. 2015. 
REDE BRASILEIRA DE ORÇAMENTOS PARTICIPATIVOS - RBOP. Relatório Técnico. Guarulhos, 2012.

RIBEIRO, A. C. T.; GRAZIA, G. de. Experiências de Orçamentos Participativos no Brasil. Petrópolis: Vozes, 2003.

RIBEIRO, L. C. de Q. SANTOS JR., O. A. dos (Orgs.). As metrópoles e a questão social brasileira. Rio de Janeiro: Revan; Fase, 2007, p. 157-161.

ROLNIK, R. Democracia no fio da navalha. Limites e possibilidades para a implementação de uma agenda de reforma urbana no Brasil. Revista Brasileira de Estudos Urbanos, v.1, n.2, nov. 2009.

SANTOS JR., O. A. dos; MONTANDON, D. T. (Orgs.). Os planos diretores municipais pósestatuto da cidade: balanço crítico e perspectivas. Rio de Janeiro: Letra Capital; Observatório das Cidades; IPPUR/UFRJ, 2011. Disponível em: < http://www.observatoriodasmetropoles. net/download/miolo_plano_diretor.pdf $>$. Acesso em: 18 dezembro 2015.

SANTOS, M. A natureza do espaço. Técnica e tempo. Razão e emoção. São Paulo: Hucitec, 1996.

SASSEN, S. As cidades na economia mundial. São Paulo: Studio Nobel, 1998.

SENNET, R. O declínio do homem público. As tiranias da intimidade. São Paulo: Cia. das Letras, 1988.

SERPA, A. O espaço público na cidade contemporânea. São Paulo: Contexto, 2007.

SINTOMER, Y.; HERZBERG, C.; ALLEGRETTI, G.; RÖCKE, A.; ALVES, M. L. Participatory Budgeting Worldwide - Updated Version. Bonn: Global Civic Engagement/ Service Agency Communities, 2013. Disponível em: < https://www.ces.uc.pt/myces/UserFiles/livros/1097_DG25_bf.pdf > Acesso em: 18 dez. 2015.

SOJA, E. W. Postmetropolis. Critical Studies of cities and regions. Oxford: Blackwell, 2001.

SOROKIN, P. A. Social mobility. Nova Iorque. Harpen and Brothers, 1927.

WAMPLER, B. Does Participatory Budgeting Deepen the Quality of Democracy? Lessons from Brazil. Comparative politics, v. 41, n. 1, p. 61-81, 2008. Disponível em: <http://sps.boisestate. edu/politicalscience/files/2010/06/Wampler-CP-2008-Lessons-from-Brazil.pdf >. Acesso em: 18 dezembro 2015. 